\title{
Application of Compromise Programming in the Energy Generation Planning
}

\author{
Fisnik Osmani, Atanas Kochov*, Mirjeta llazi
}

\begin{abstract}
The need for the right electricity planning is closely related to the analysis that has to be done on its generating capacity. Of course, in order to make such planning, the choice of the method by which the process is carried out must be considered. The inclusion of multiple objectives (goals) enables us to create models that are useful in researching and expanding electricity generation systems. Compromised programming used in this paper aims to find compromise solutions among different conflicting objectives in the electricity generation system. One such case is the goal of minimizing the cost and $\mathrm{CO} 2$ emissions. Using this logic, the paper deals with an example of electricity generation planning for a given region.
\end{abstract}

Keywords: compromising programming; emissions; energy planning; generation costs; MCDM

\section{INTRODUCTION}

This paper assumes annual electricity which can be generated by the use of available energy sources including: coal, wind energy, biomass, hydropower, and solar energy. With the application of compromise programming, taking into account the minimization of energy generation cost and $\mathrm{CO}_{2}$ emissions, the optimal solution is achieved by calculating groups of compromise for different weights.

As a concept, planning can be defined as the first and the most basic function of management. When planning needs to be based on results and a lot of goals, then of course the right methods are needed, in order for optimal solutions to be acheived. The linear programming method, as the traditional approach to modeling decisions about power generation, relies on some basic assumptions about situation modeling and in this approach the decision maker intends to choose a well-defined objective.

The transition from the current electricity system to a renewable electricity supply poses immense economic, technological, and policy challenges. Energy system models represent the complexity of interactions in combined processes from extraction of primary energy to the use of the final energy to supply services and goods. [1]

Last year, important changes in the sectors of energy supply have happened, which have had important implications for energy planning. By 2050, 49-67\% of primary energy will be supplied by renewable energy sources (RES), by lowering energy use and decarbonizing energy supply in the built-up environment [2]. Electricity generation has some environmental impacts, which however are not taken into account when allocating resources efficiently. According to an estimate, gross demand for energy in Kosovo is expected to increase by $4.6 \%$ a year over the 2010 2025 periods. [3]

Defining objectives is an essential part of the planning process, useful to induce creative alternatives and to derive the attributes (criteria) on which the alternatives will be assessed. Practically, the decision maker seeks consistent compromise between several objectives, many of which may be in conflict with one another. In addition to the economic issue, an emission issue should also be considered in the operation of an industrial consumer in order to reduce greenhouse gases like $\mathrm{NO}_{2}, \mathrm{SO}_{2}$, and $\mathrm{CO}_{2}$ in the atmosphere. $[4,5]$

This paper provides a simplified electricity planning model with some energy planning assumptions in order to reduce operational complexity. The introduction of environmental costs is done through a related variable, such as $\mathrm{CO}_{2}$ emissions of environmental sustainability.

Based on international analysis and reports for the Western Balkans, it is clear in what indicators / key components the greatest focus is required

The inclusion of multiple objectives (goals) enables us to create models that are useful in researching and expanding electricity generation systems. Multi Criteria Decision Making Method is the method preferred by many authors, referring to the Compromise, Topsis, Pareto, Electre, Promethee, AHP method etc. [6-9].

The conceptual approach applied in the paper where we are limited to only two purposes, namely the cost of generation and emissions, requires an additional discussion because other methods with the inclusion of more factors are currently available.

\section{ELECTRICITY GENERATION PLANNING, THROUGH THE APPLICATION OF COMPROMISED PROGRAMMING. \\ 2. 1 Formulation of the Problem within the Conditions of Republic of Kosovo}

For our region, annual electricity consumption is 5000 GWh [10], which can be generated by the use of the following energy sources: coal, wind power, biomass, Hydropower, and solar power. The cost of generation, as well as the generated environmental emissions, should be minimal.

Tab. 1 shows the generation costs and $\mathrm{CO}_{2}$ emissions for the options considered. To refer to electricity output, both options are set in relation to the $\mathrm{kWh}$ generated.

Under these assumptions, the formulation of the problem is: 
Minimized $z(x)=\left[z_{1}(x), z_{2}(x)\right]$

$$
\begin{aligned}
& z_{1}(x)=\left(c_{1} x_{1}+c_{2} x_{2}+c_{3} x_{3}+c_{4} x_{4}+c_{5} x_{5}\right) / \sum x_{i}, \text { euro } / \mathrm{MWh} \\
& z_{2}(x)=\left(e_{1} x_{1}+e_{3} x_{3}\right) / \sum x_{i}, \mathrm{~g} / \mathrm{MWh} \\
& z_{1}(x)=\left(28 x_{1}+85 x_{2}+71 x_{3}+77.3 x_{4}+136.5 x_{5}\right) / \sum x_{i}, \text { euro } / \mathrm{kWh} \\
& z_{2}(x)=\left(1015 x_{1}+101 x_{3}\right) / \sum x_{i}, \mathrm{~g} / \mathrm{kWh}
\end{aligned}
$$

The above functions are subjected to the following limitations

\begin{tabular}{|c|c|c|c|c|c|c|c|}
\hline $\mathrm{Nr}$. & $\begin{array}{c}\text { Energy } \\
\text { source }\end{array}$ & Cor & $\begin{array}{l}\text { mption, } \\
\text { a/year }\end{array}$ & $\operatorname{Cos}$ & , euro/MWh & & $\begin{array}{l}\text { ssions } \\
\mathrm{g} / \mathrm{kWh}\end{array}$ \\
\hline 1 & Coal & $x_{1}$ & 4000 & $c_{1}$ & 28 [11] & $e_{1}$ & 1015 \\
\hline 2 & Wind & $x_{2}$ & 200 & $c_{2}$ & 85 [12] & $e_{2}$ & \\
\hline 3 & Biomass & $x_{3}$ & 100 & $c_{3}$ & $71[12]$ & $e_{3}$ & 101 \\
\hline 4 & Hydropower & $x_{4}$ & 500 & $c_{4}$ & $77.3[12]$ & $e_{4}$ & \\
\hline 5 & Solar & $x_{5}$ & 200 & $c_{5}$ & $136.4[12]$ & $e_{5}$ & \\
\hline \multicolumn{2}{|c|}{ Energy Demand } & & 5000 & & & & \\
\hline
\end{tabular}

$$
\begin{aligned}
& \sum x_{i} \geq 5000 \mathrm{GWh} ; x_{i} \geq 0, \forall i \\
& x_{2} \leq 200 \mathrm{GWh} ; x_{3} \leq 100 \mathrm{GWh} \\
& x_{4} \leq 500 \mathrm{GWh} ; x_{5} \leq 200 \mathrm{GWh} .
\end{aligned}
$$

Table 1 Consumption, costs and emissions of $\mathrm{CO}_{2}$ from electricity generation $[11,12$

\subsection{Application of Multi-Objective Programming}

Multi-criteria decision-making, or MCDM [13], is implemented when there are some contradictory criteria, that is to say, several criteria that matter but cannot be optimized at the same time, especially in energy problems. Multiobjective programming or vectorial optimization $[15,14]$ techniques address the simultaneous optimization of some of the objectives that are subject to a set of commonly linear constraints, since an optimization solution cannot be determined for some objectives, MOP is used to gain community potential solutions that are efficient solutions (Pareto Optimal) rather than finding a single optimal solution. The elements of this efficient group are the possible solutions so there are no other possible solutions that can achieve the same or better performance for all objectives and in the best way for at least one objective.

Thus, to generate an efficient MOP, a model group can be formulated as follows:

Eff. $z(x)=\left[z_{1}(x), \ldots, z_{q}(x)\right]$, based on $x \in F$.

When Eff. means seeking efficient solutions (in terms of minimizing and maximizing).

$F$, on the other hand, represents the possible group, and $\mathrm{x}$ indicates the vector of decision variables. Therefore, based on this, in our case, first, it is necessary to calculate the elements of the cost matrix [15]. This matrix is the result of the optimization of each objective, the costs of electricity generation, and $\mathrm{CO}_{2}$ emissions separately, giving the second goal the appropriate value for optimal solution of the first. Thus, a square matrix is obtained in which the level of conflict between the goals is reflected rather than finding a single optimal solution. The elements of this efficient group are the possible solutions. There are no other possible solutions that can achieve the same or better performance for all objectives, or in the best way for at least one objective. Thus to generate an efficient MOP model group can be formulated as follows: Eff. $z(x)=\left[z_{1}(x), \ldots z_{\mathrm{q}}(x)\right]$

Optimization is done with the application of the phpsimpleex program [16], from which we get the solutions: Minimizing the cost $z_{1}(x)$, the following solution is obtained: Cost, $z_{1}(x)=28.00$ euro/kWh and emissions $\mathrm{CO}_{2}, z_{2}(x)=$ $1015 \mathrm{~g} / \mathrm{kWh}$ with: $x_{1}=5000 \mathrm{GWh}$ of coal and other components $x_{2}=0 ; x_{3}=0 ; x_{4}=0 ; x_{5}=0$.

The interpretation that can be done is to maximize the use of coal, which generates the lowest cost that it has. Minimizing $\mathrm{CO}_{2}$ emissions $z_{2}(x)$, we gain:

Cost $z_{1}(x)=40.41$ euro/MWh and $\mathrm{CO}_{2}$ emissions $z_{2}(x)=$ $814.02 \mathrm{~g} / \mathrm{kWh}$ with: $x_{1}=4000 \mathrm{GWh}, x_{2}=200 \mathrm{GWh}, x_{3}=100$ GWh, $x_{4}=500 \mathrm{GWh}, x_{5}=200 \mathrm{GWh}$.

In this case, they make most of all clean energy sources, making the coal meet the fixed total needs. The gained values of optimism with the application of the simplex method [17] are listed in Tab. 3 .

Table 2 Ideal and Anti-Ideal Points used in Compromise Programming

\begin{tabular}{|l|c|c|}
\hline & Cost, euro/MWh & Emission $\mathrm{CO}_{2}, \mathrm{~g} / \mathrm{kWh}$ \\
\hline Cost & 28.00 & 1015.00 \\
\hline Emission $\mathrm{CO}_{2}$ & 40.41 & 814.02 \\
\hline
\end{tabular}

The main diagonal elements are called ideal locations, hence the solution in which both goals (objectives) reach their optimum value. In reality, the ideal point is unattainable, but it is useful to determine the most appropriate solution in order to homogenize decision-making units. The most appropriate solution should be chosen from the group of efficient solutions. This group can be approximated by the limitation method.

This method optimizes a goal (objective), including other constraints set as a parametric barrier. For each value of this parameter, a certain point of efficient solutions will be gained. The method in our case, has been applied, in minimizing the cost, for a number of relevant values of $\mathrm{CO}_{2}$ emissions. This group is determined by ideal and anti-ideal emission values, for an increase of $10 \mathrm{~g} / \mathrm{kWh}$ variation.

The formulation is as follows:

$$
\begin{aligned}
& z_{1}(x)=\left(28 x_{1}+85 x_{2}+71 x_{3}+77.3 x_{4}+136.5 x_{5}\right) / \sum x_{i}, \text { euro } / \mathrm{kWh} \\
& z_{2}(x)=\left(1015 x_{1}+101 x_{3}\right) / \sum x_{i}, \mathrm{~g} / \mathrm{kWh}
\end{aligned}
$$

The subject and the following restrictions

$\sum x_{\mathrm{i}} \geq 5000 \mathrm{GWh} ; x_{i} \geq 0, \forall i$

$x_{2} \leq 200 \mathrm{GWh} ; x_{3} \leq 100 \mathrm{GWh} ; x_{4} \leq 500 \mathrm{GWh}$;

$z_{2}(x)=k, 814.02<k<1015.00$

The gained values are shown in Tab. 3. In this table, the participation of different items in the generation of electricity 
for the options being considered can be observed. We can see how many different options are coming up with optimal solutions as we change the cost of $\mathrm{CO}_{2}$ generation and emission. Thus, for example, wind energy only enters the solution when $\mathrm{CO}_{2}$ emissions are limited to $904.02 \mathrm{~g} / \mathrm{kWh}$, bringing the cost of production to 33.36 euros $/ \mathrm{kWh}$. However, if the cost of generation is limited, for example, $30.93 \mathrm{euro} / \mathrm{kWh}$, we only have room for the optimal mix of coal, biomass, and hydropower generation.

Table 3 Efficient set of solutions

\begin{tabular}{|c|c|c|c|c|c|c|c|}
\hline \multicolumn{3}{|c|}{ ENERGY SOURCE } & COAL & WI. & BIOM. & HYD. & SOL \\
\hline \multicolumn{2}{|c|}{ Cost of energy production } & 28 & 85 & 71 & 77.3 & 136.4 \\
\hline Nr. & $z_{1}(x)$ & $z_{2}(x)$ & $x_{1}$ & $x_{2}$ & $x_{3}$ & $x_{4}$ & $x_{5}$ \\
\hline 1 & 40.41 & 814.02 & 4000 & 200 & 100 & 500 & 200 \\
\hline 2 & 39.34 & 824.02 & 4049 & 200 & 100 & 500 & 151 \\
\hline 3 & 38.27 & 834.02 & 4099 & 200 & 100 & 500 & 101 \\
\hline 4 & 37.20 & 844.02 & 4148 & 200 & 100 & 500 & 52 \\
\hline 5 & 36.13 & 854.02 & 4197 & 200 & 100 & 500 & 3 \\
\hline 6 & 35.54 & 864.02 & 4246 & 154 & 100 & 500 & 0 \\
\hline 7 & 34.98 & 874.02 & 4296 & 104 & 100 & 500 & 0 \\
\hline 8 & 34.42 & 884.02 & 4345 & 55 & 100 & 500 & 0 \\
\hline 9 & 33.86 & 894.02 & 4394 & 6 & 100 & 500 & 0 \\
\hline 10 & 33.36 & 904.02 & 4443 & 0 & 100 & 457 & 0 \\
\hline 11 & 32.88 & 914.02 & 4493 & 0 & 100 & 407 & 0 \\
\hline 12 & 32.39 & 924.02 & 4542 & 0 & 100 & 358 & 0 \\
\hline 13 & 31.91 & 934.02 & 4591 & 0 & 100 & 309 & 0 \\
\hline 14 & 31.42 & 944.02 & 4640 & 0 & 100 & 260 & 0 \\
\hline 15 & 30.93 & 954.02 & 4690 & 0 & 100 & 210 & 0 \\
\hline 16 & 30.45 & 964.02 & 4739 & 0 & 100 & 161 & 0 \\
\hline 17 & 29.96 & 974.02 & 4788 & 0 & 100 & 112 & 0 \\
\hline 18 & 29.48 & 984.02 & 4837 & 0 & 100 & 63 & 0 \\
\hline 19 & 28.99 & 994.02 & 4887 & 0 & 100 & 13 & 0 \\
\hline 20 & 28.52 & 1004.02 & 4940 & 0 & 60 & 0 & 0 \\
\hline 21 & 28.05 & 1014.02 & 4995 & 0 & 5 & 0 & 0 \\
\hline 22 & 28.00 & 1015.02 & 5000 & 0 & 0 & 0 & 0 \\
\hline
\end{tabular}

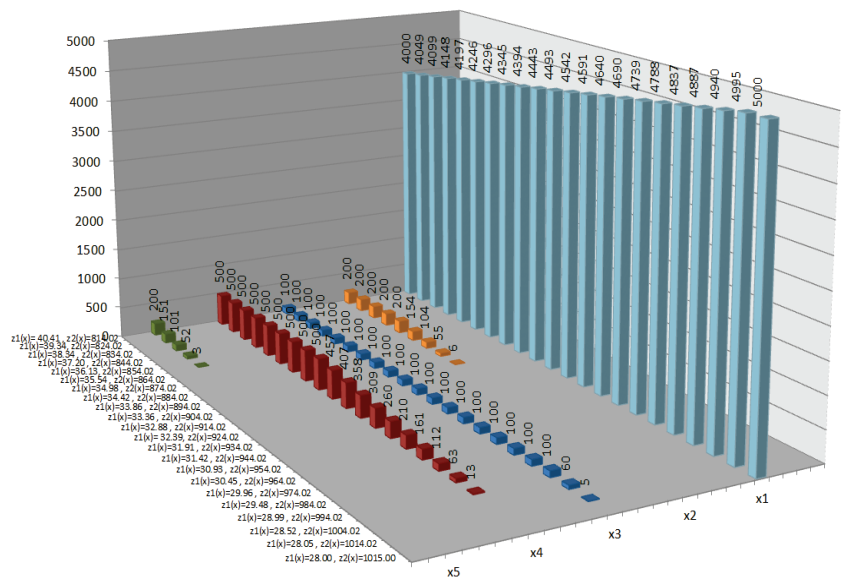

Figure 1 Total efficient solution from Tab. 3

With the obtained values, the graph is developed, which also points to the ideal point. All the solutions represented on the curve graph are viable and efficient solution. But to solve the problem, it is necessary to choose one of the items. In our case, such is the value of the minimum generation cost or the minimum emission of $\mathrm{CO}_{2}$, where the optimal point will move along the right or left curve.

Therefore, the displayed curve provides decision-making assistance because it shows all of those efficient optimization solutions to the problem in order to find the solution that best suits the interests of decision-makers. So, it seems that in the group of solutions, it is possible to choose an optimal solution, by means of compromise programming, described below.

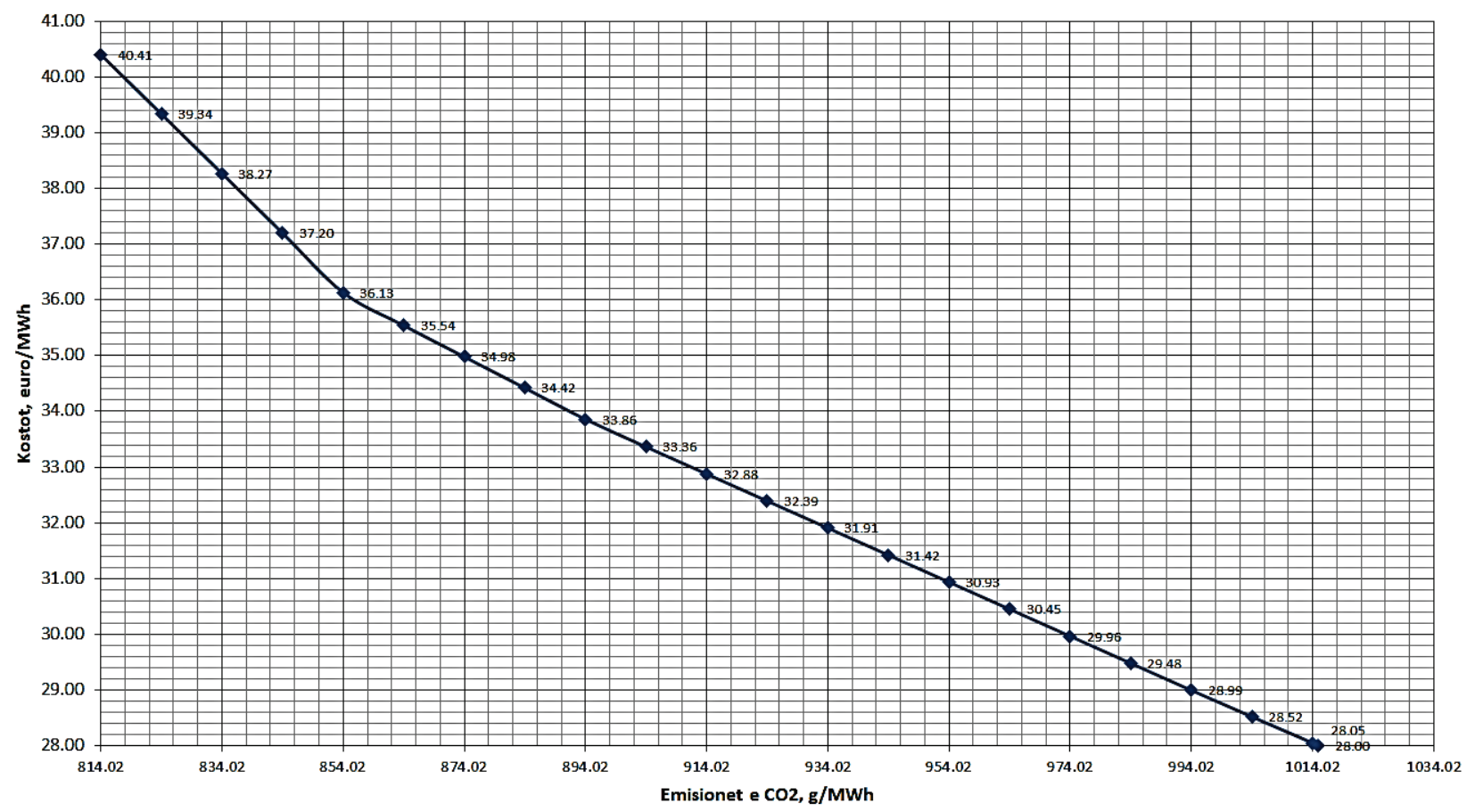

Figure 2 Compromise group for equal weight criteria 


\section{COMPROMISE PROGRAMMING}

The compromise programming was used to select the optimal element from a range of efficient solutions as proposed by Zeleny. This rule is called Zeleny's axiom and is expressed as follows: "Taking into consideration solutions in $\operatorname{target}$ space $\mathrm{z}_{1}$ and $\mathrm{z}_{2}$, the preferred solution will be the closest to the ideal point" (Zeleny 1973, 74) [18].

If we consider that the decision-making center behaves in a rational way, it will select that effective point or zone of effective point groups that are closer to the ideal point.

Compromising programming begins by setting the ideal point, the coordinates of which are given by the optimum values of the various objectives of the decision-maker. The ideal point is usually inadequate. If possible, then there is no conflict between the objectives. When the ideal point is inadequate, the optimal elements or compromise solutions are provided by an efficient solution that is closer to the ideal point.

The ideal alternative coordinates are given by optimal values usually when targets (goals) are measured in different units, so that the amount of proximity stakes does not make sense, without having dimensional homogeneity. Therefore, it will be necessary to continue with the normalization of objectives (goals). Thus, the degree of proximity as the relative deviation between the $\mathrm{j}$ objective and its ideal value is determined by:

$d_{j}=\frac{\left[z_{j}^{*}-z_{j}(x)\right]}{\left[z_{j}^{*}-z_{* j}\right]}$

where $d_{j}$ represents the degree of proximity of the normalized objective $j$ and $z^{*} \mathrm{j}$ is the anti-ideal of this objective - the worst possible value for objective $j$ in an effective set (efficiency). The normalized degree of proximity is limited between 0 and 1 . Thus, when a target reaches its ideal value, its proximity is zero; on the contrary, this scale becomes equal to one when the objective in question reaches an equal value with the anti-ideal. If we now represent $W_{j}$ preferences that the decision-making center relates to the discrepancy between achieving the $j$ and its ideal goal, compromise programming is consistently consistent in seeking more efficient solutions closer to the ideal. So, this programming process is based on whether the optimal solution is to find the closest point to the ideal. This proximity is measured by the mathematical concept of distance.

There are many distances, apart from the Euclidean, the best known, and the question is which ones should be used. In fact, the process simplifies, as it is shown that the range of distance solutions from the ideal point is the one that is minimal, the so-called distance of Manhattan $L_{1}$ and Chebysev $L_{\infty}$ respectively are minimal.

These points are unchanged as they depend on the given weighting (weighting) of each known target and must reflect the preferences of the decision-making center. These weights are placed in the expression of the distance, so that the result is as follows:

$$
\begin{aligned}
& L_{1}=W_{1} \frac{z_{1}(x)-z_{1}^{*}}{z_{* 1}-z_{1}^{*}}+W_{2} \frac{z_{2}(x)-z_{2}^{*}}{z_{* 2}-z_{2}^{*}} \\
& L_{\infty}=\max \left[W_{1} z_{1}(x)-z_{1}^{*}, W_{2} z_{2}(x)-z_{2}^{*}\right]
\end{aligned}
$$

where: $z_{j}^{*}$ - the ideal value, $z_{* j}$ - the anti-ideal value, $W_{j}$ - the weight of each objective.

For example, we have calculated the tradeoffs for different weights. Here, the same weighting is considered for the two objectives, twice more important for one of them, and also one of them four times more important than the other. The resulting groups of compromise are shown in Tab. 4

Table 4 Compromise solutions $L_{1}$ and $L_{\infty}$

\begin{tabular}{|c|c|c|c|c|c|c|c|c|}
\hline \multirow{2}{*}{ Weight factor } & \multirow{2}{*}{ Distance } & Cost & Emission $\mathrm{CO}_{2}$ & Coal & Win. & Bio. & Hyd. & Solar \\
\cline { 3 - 9 } & & euro/MWh & $\mathrm{g} / \mathrm{kWh}$ & GW/year & GW/year & GW/year & GW/year & GW/year \\
\hline$W_{1}=1$ & $L_{1}$ & 36.55 & 850.17 & 4178 & 200 & 100 & 500 & 22 \\
\hline$W_{2}=1$ & $L_{\infty}$ & 36.33 & 852.15 & 4188 & 200 & 100 & 500 & 12 \\
\hline$W_{1}=1$ & $L_{1}$ & 33.30 & 905.37 & 4450 & 0 & 100 & 450 & 0 \\
\hline$W_{2}=0.8$ & $L_{\infty}$ & 34.11 & 889.58 & 4372 & 28 & 100 & 500 & 0 \\
\hline$W_{1}=1$ & $L_{1}$ & 34.38 & 884.65 & 4348 & 52 & 100 & 500 & 0 \\
\hline$W_{2}=0.9$ & $L_{\infty}$ & 35.00 & 873.71 & 4294 & 106 & 100 & 500 & 0 \\
\hline$W_{1}=08$ & $L_{1}$ & 36.34 & 852.05 & 4187 & 200 & 100 & 500 & 13 \\
\hline$W_{2}=1$ & $L_{\infty}$ & 38.23 & 834.39 & 4100 & 200 & 100 & 500 & 100 \\
\hline$W_{1}=0.9$ & $L_{1}$ & 36.44 & 851.11 & 4183 & 200 & 100 & 500 & 17 \\
\hline$W_{2}=1$ & $L_{\infty}$ & 37.83 & 838.12 & 4119 & 200 & 100 & 500 & \\
\hline
\end{tabular}

For example, we calculated the groups of compromises for different weights. Here the division of the same weight is considered for both objectives, $\left(W_{1}=1, W_{2}=1\right),\left(W_{1}=1, W_{2}\right.$ $=0.9),\left(W_{1}=1, W_{2}=0.8\right)$ and $\left(W_{1}=1, W_{2}=1\right),\left(W_{1}=08, W_{2}\right.$ $=1),\left(W_{1}=0.9, W_{2}=1\right)$. The weight groups, placed in the expression of the distance $\left(L_{1}, L_{\mathrm{inf}}\right)$, resulting in compromise, are reflected in Tab. 3 .

Any type of energy in optimal solutions can be seen in Tab. 2, introducing the cost of generation and the respective
$\mathrm{CO}_{2}$ emissions. As an illustration, a compromise has been made in detail on the case of the same importance for two objectives that are considered certain.

This compromise set is graphically shown in Fig. 4.

As it can be observed, wind energy appears in this set of compromises, albeit with a slightly lower share. However, solar energy does not appear, because the generation cost is very high, as shown in Tab. 5 that is observed. 


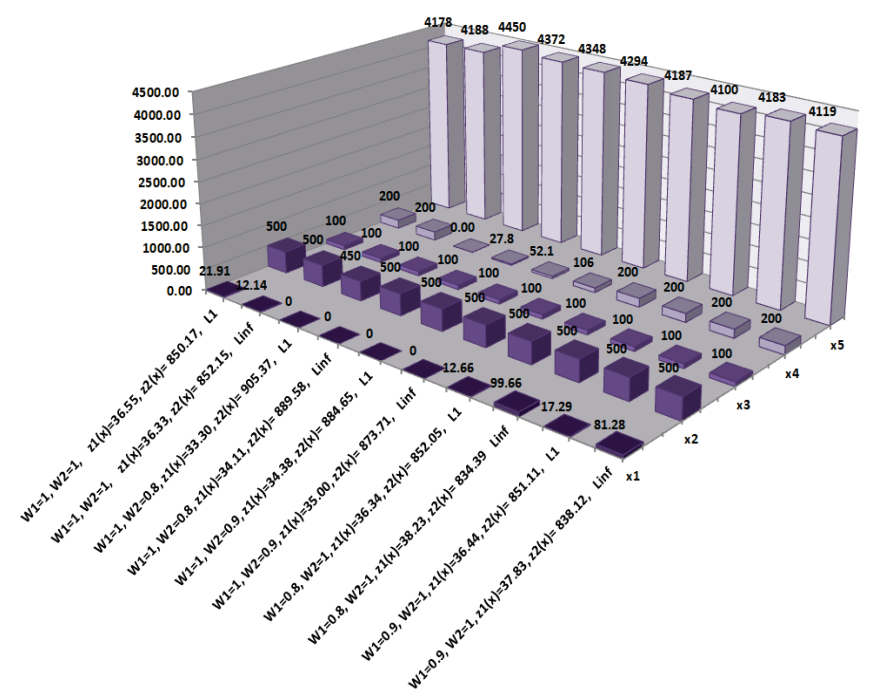

Figure 3 Graphically solutions of $L_{1}$ and $L_{\infty}$

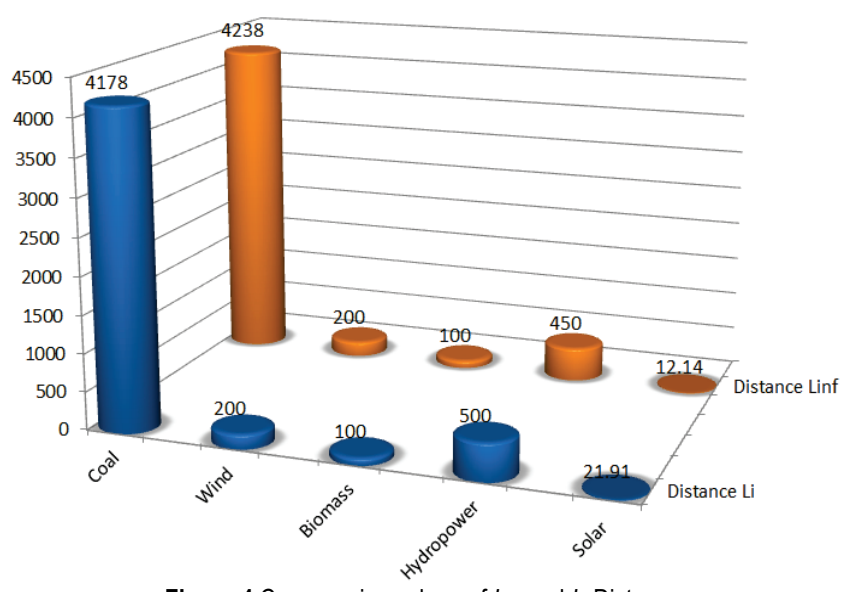

Figure 4 Compromise values of $L_{\text {inf }}$ and $L_{i}$ Distance

Table 5 Compromise solutions for energy sources $L_{1}$ and $L_{\infty}$

\begin{tabular}{|c|c|c|}
\hline Energy Sources & Distance $L_{\mathrm{i}}$ & Distance $L_{\infty}$ \\
\hline Coal & 4178.09 & 4237.85 \\
\hline Wind & 200 & 200 \\
\hline Biomass & 100 & 100 \\
\hline Hydropower & 500 & 450 \\
\hline Solar & 21.91 & 12.14 \\
\hline
\end{tabular}

\section{CONCLUSION}

Optimization is an engineering discipline where extreme values of design criteria are required and often there are numerous conflicting criteria to be addressed. Meeting one of these criteria comes at the expense of another. Therefore, multi-purpose optimization deals with conflicting objectives. From various papers presented in the literature, it is noted that no single optimization approach is superior; rather, the selection of a specific optimization method depends on the type of information given in the problem, designer preferences, solution requirements, and the availability of software application.

In the treated example of electricity planning for a given region, the introduction of the $\mathrm{CO}_{2}$ emission criterion along with generation costs modifies the outcome of the electricity planning. So by reducing the amount of coal, the more expensive options are offered, but with lower $\mathrm{CO}_{2}$ emissions. The simplifications used for this example are useful in that the results are used not as absolute values but rather as indicators for decision making. In-depth analysis would include better definition of assumptions, taking into account a greater number of criteria for decision-making, such as other socio-economic or environmental variables.

The compromised programming approach gives the decision maker the most efficient system for generating electricity, which is closer to reality than that achieved by optimizing a single objective, as has been done in the past. But besides programming with compromise, actually the analytical hierarchy process method [19] is quite preferred by decision-makers. Although AHP is not without theoretical difficulty, its iterations with a decision-making team makes it a very convenient tool to extract preferential weight within the context of energy planning.

\section{Notice}

The paper was presented at MOTSP 2020 - International Conference Management of Technology - Step to Sustainable Production, which took place from $30^{\text {th }}$ September $-2^{\text {nd }}$ October 2020 in Bol, island Brač (Croatia). The paper is not and will not be published anywhere else.

\section{REFERENCES}

[1] Tobias, W., Marcel, D., \& Jutta, F. (2019). Combining scenario planning, energy system analysis, and multicriteria analysis to develop and evaluate energy scenarios. Journal of Cleaner Production, 242, 118414. https://doi.org/10.1016/j.jclepro.2019.118414

[2] Lobaccaro, G., Croce, S., Lindkvist, C., Munari Probst, M. C. Scognamiglio, A., Dahlberg, J., Lundgren, M., \& Wall, M. (2019). A cross-country perspective on solar energy in urban planning: Lessons learned from international case studies. Renewable and Sustainable Energy Reviews, 108, 209-237. https://doi.org/10.1016/j.rser.2019.03.041

[3] Building stock study-Kosovo, World Bank, 2016.

[4] Lee, N. C., Leal, V. M. S., \& Dias, L. C. (2018). Identification of objectives for national energy planning in developing countries. Energy Strategy Reviews, 21, 218-232. https://doi.org/10.1016/j.esr.2018.05.004

[5] Khodaei, H., Hajiali, M., Darvishan, A., Sepehr, M. \& Ghadimi, N. (2018). Fuzzy-based heat and power hub models for cost-emission operation of an industrial consumer using compromise programming. Applied Thermal Engineering, 137, 395-405. https://doi.org/10.1016/j.applthermaleng.2018.04.008

[6] Kasprzak, E. M. \& Lewis, K. E. (2001) Pareto analysis in multiobjective optimization using the collinearity theorem and scaling method. Struct Multidisc Optim, 22, 208-218. https://doi.org/10.1007/s001580100138

[7] Kolios, A., Mytilinou, V., Lozano-Minguez, E., \& Salonitis, K. (2016). A Comparative Study of Multiple-Criteria DecisionMaking Methods under Stochastic Inputs. Energies MDPI. Basel, Switzerland. https://doi.org/10.3390/en9070566

[8] Saaty, T. L. (1980). Multicriteria Decision Making: The Analytic Hierarchy Process. McGraw-Hill, New York. https://doi.org/10.21236/ADA214804 
[9] Saaty, T. L. \& Gholamnezhad, A. H. (1982). High-Level Nuclear Waste Management: Analysis of Options. Environmental Planning, 9, 181-196. https://doi.org/10.1068/b090181

[10] Energy Strategy of the Republic of Kosovo 2017 - 2026

[11] Kosovo Energy Corporation - Kosovo B Thermal Power Plant Division B January 2020

[12] Evaluation of Power Supply Option for Kosovo, the World Bank - IBRD -IDA / World Bank Group, August 2018.

[13] Pohekar, S. D. \& Ramachandran, M. (2004). Application of multi-criteria decision making to sustainable energy planning-A review. Renewable and Sustainable Energy Reviews, 8, 365-381. https://www.elsevier.com/locate/rser https://doi.org/10.1016/j.rser.2003.12.007

[14] Odu, G. O. \& Charles-Owaba, O. E. (2013). Review of Multicriteria Optimization Methods - Theory and Applications. IOSR Journal of Engineering (IOSRJEN), 3(10). https://doi.org/10.9790/3021-031020114

[15] Projected Costs of Generating Electricity. 2015 Edition, International Energy Agency Nuclear Energy Agency Organisation for Economic Co-Operation and Development. https://www.solar-united.org/wp-content/uploads/2017/02/ ElecCost2015SUM.pdf

[16] Simplex method software - www.phpsimpleex.com

[17] Luenberger, D. G. \& Ye, Y. (2008). Linear and Nonlinear Programming, Fourth Edition, Stanford University, p. 72.

[18] Cochrane, J. L. \& Zeleny, M. (1973). Compromise programming in multiple criteria decision making, University of South Carolina Press, Columbia.

[19] Saaty, T. L. \& Kats, J. M. (1990). How to make a decision: The analytic hierarchy process. European Journal of Operational Research, 48(1), 9-26.

https://doi.org/10.1016/0377-2217(90)90057-I

\section{Authors' contacts:}

Fisnik Osmani, Prof. ass. dr. University of Mitrovica,

Faculty of Mechanical Engineering and Computer, Ukshin Kovaqica, 40000 Mitrovica, Kosovo

fisnik.osmani@umib.net

Atanas Kochov, Prof. dr.

(Corresponding author)

University "St. Kiril \& Methodius",

Faculty of Mechanical Engineering,

Karpos II bb 1000 Skopje, North Macedonia

atanas.kochov@mf.edu.mk

Mirjeta llazi, MSc, PhD Candidate

University "St. Kiril \& Methodius",

Faculty of Mechanical Engineering,

Karpos II bb 1000 Skopje, North Macedonia 